\title{
Genital Ulcers in Women: Clinical, Microbiologic and Histopathologic Characteristics
}

\author{
Christiane Maria Moreira Gomes ${ }^{1}$, Paulo César Giraldo ${ }^{2}$, Francis de Assis Moraes Gomes ${ }^{3}$, Rose Amaral ${ }^{4}$, \\ Mauro Romero Leal Passos ${ }^{5}$ and Ana Katherine da Silveira Gonçalves ${ }^{6}$ \\ ${ }^{1}$ Dermatologist, postgraduate student in the Master's program, DTG/FCM/Unicamp, ${ }^{2}$ Associate Professor and Faculty Member in the \\ Department of Obstetrics and Gynecology, FCM/Unicamp, ${ }^{3}$ Physician in the Female Genital Infections Outpatient Facility of FCM/UNICAMP, \\ Doctor in Obstetrics and Gynecology, doctoral thesis defended at Unicamp, ${ }^{4}$ Physician specialized in Obstetrics and Gynecology, postgraduate \\ student in the Master's Program, DTG/FCM/Unicamp, ${ }^{5}$ Professor and Doctor in the Department of Microbiology and Parasitology, UFF; \\ ${ }^{6}$ Professor and Doctor in the Department of Gynecology, UFRGN; Campinas, SP, Brazil
}

Female genital ulcer is a disease that affects a large number of women, and its etiologic diagnosis can be difficult. The disease may increase the risk of acquiring HIV. Genital ulcer may be present in sexually transmitted diseases (STD) - syphilis, chancroid, genital herpes, donovanosis, lymphogranuloma venereum and other non-STD disorders (NSTD) - Behçet's syndrome, pemphigus, Crohn's disease, erosive lichen planus and others. This study evaluated the clinical-histopathologic-microbiologic characteristics of female genital ulcers. A cross-sectional descriptive prospective study was conducted during a six-month period to investigate the first 53 women without a definitive diagnosis, seeking medical care for genital ulcers at a genital infections outpatient facility in a university hospital. A detailed and specific history was taken, followed by a dermatologic and gynecologic examination. In addition to collecting material from the lesions for microbiologic study, a biopsy of the ulcer was performed for histopathologic investigation. The average age of the patients was 32.7 years, $56.6 \%$ had junior high school education and higher education. The most frequent etiology was herpetic lesion, followed by auto-immune ulcers. At the time of their first consultation, around $60 \%$ of the women were using inadequate medication that was inconsistent with the final diagnosis. Histologic diagnosis was conclusive in only $26.4 \%$ of the patients (14/53). Cure was obtained in $99 \%$ of the cases after proper therapy. The female genital ulcers studied were equally distributed between sexually transmitted and non-sexually transmitted causes. Herpes was the most frequent type of genital ulcer, affecting women indiscriminately, mostly between the ages of 20 and 40 years. The etiologic diagnosis of herpetic ulcers is difficult to make even when various diagnostic methods are applied. It is imperative that NSTD should be included in the differential diagnoses of female genital ulcers. The histopathologic exam is not a diagnostic tool in the majority of cases and should not be considered the gold standard test, being of little value in cases of NSTD and STD ulcers. Key-Words: Female genital ulcer, STD, herpes virus, Behçet's syndrome, syndromic ulcer management, vulvar disease, vulvar vasculitis.

The female genital region may be the site of various organic disorders, and genital ulcers (GU) are very frequent conditions [1]. The unique location and anatomic disposition of the genital region hinder self-examination of the vulva. Furthermore, the warm humid environment of the region alters the morphology of various disorders [2]. The gynecologist usually pays little attention to the vulva, frequently leading to errors in interpretation of different lesions of the vulvar cutaneous tissue, making diagnosis difficult [2]. By definition, an ulcer is a break in the continuity of the skin and/or mucous membrane, involving tissue loss of the epidermis, dermis and hypodermis [3].

Female genital ulcers are the first manifestations of many diseases, arising from tissue necrosis due to cell injury caused by intense focal inflammatory and ischemic processes. In several cases, tissue lesion (necrosis) results from ischemic, autoimmune or even irritative phenomena, and is not simply due to sexually transmitted infections [2].

Received on 21 August 2006; revised 17 February 2007.

Address for correspondence: Dr. Paulo César Giraldo. Rua Dom Francisco de Campos Barreto145, Nova Campinas, Campinas, SP - Zip code: 13092-360. Brazil. Phone (5519) 3788-9406. E-mail: giraldo@unicamp.br.

The Brazilian Journal of Infectious Diseases 2007;11(2):254-260. (c) 2007 by The Brazilian Journal of Infectious Diseases and Contexto Publishing. All rights reserved.
Given the large number of differential diagnoses and the practical difficulties in establishing a clear-cut etiologic diagnosis, there is usually a correct and prudent tendency for healthcare providers to initially consider every female genital ulcer as a sexually transmitted disease (STD). The World Health Organization (WHO) and the Brazilian Ministry of Health (MH) strongly recommend the syndromic management of genital ulcers at the first contact of the patient with the health clinic. This practice is aimed at curing the disease and also reducing the risks for acquiring other STD, especially AIDS [4]. However, in many cases, empirical treatment may not resolve the lesion, masking the problem and even causing marital discord, since the lesion is treated as an STD, when in fact it is not [4].

Genital ulcers (GU) are one of the main signs of various disorders that have afflicted humanity since ancient times, often representing a diagnostic dilemma [5,6]. These ulcers may vary in presentation according to etiology, length of clinical course, age and immunity of the host, leading to diagnostic confusion and unsatisfactory therapeutic results. Therefore, a detailed medical history and physical examination are required for management of these lesions, associated with supplementary exams $[7,8]$.

Female genital ulcers (FGU) have been of global concern to health programs in recent years, not only because of bodily discomfort inherent in the disease, but also because FGU are 
intimately related to high rates of AIDS transmission [9]. Furthermore, female genital ulcers may play an important role in the diagnosis of vulvar malignant tumors [10].

Briefly and for didactic purposes, genital ulcers may be divided into ulcers caused by sexually transmitted diseases (GU-STD) and those caused by non-sexually transmitted diseases (GU-NSTD) [5]. Cited among ulcers caused by STD are: syphilis, chancroid, lymphogranuloma venereum, donovanosis and genital herpes. In the literature, evidence demonstrates that STD can increase the risk for acquiring human immunodeficiency virus (HIV) infection up to 18 times in sexually active women. This occurs especially when STD produce genital ulcers, significantly enhancing the vulnerability of these women [11,12]. African papers and those of other sources corroborate these statements [13-16]. Noninfectious ulcers (GU-NSTD) are mainly due to trauma, drug reactions, acne, diseases characterized by vesiculobullous pattern (pemphigus, erythema multiforme), Behçet's disease, Reiter's syndrome (ulcer, arthritis and uveitis), Crohn's disease, neoplasms, Queirat's erythroplasias, Paget's disease, Lishtpuetz ulcers (Ulcus), Bowen's disease, among others such as bipolar and complex aphthous ulceration, ulcerative retocolitis, lichen planus and bullous dermatosis due to linear IgA [5,17-19].

As one can expect, it is very difficult to rapidly establish a clear and definitive etiologic diagnosis of FGU. In order to avoid treatment errors, it would be interesting if every physician caring for patients with FGU knew the major manifestations of the variety of diseases. Studies that fully describe the frequency of different causes of FGU in each region are advisable, as well as their main clinical, microbiologic and histologic characteristics for safer application of syndromic management.

\section{Materials and Methods}

A descriptive observational study was conducted to evaluate 53 women with genital ulcers, who sought the female genital infections outpatient facility (FGIOF) in the Department of Obstetrics and Gynecology, University of Campinas, during a six-month period (March to September 2005). The project was evaluated and approved by the Research Ethics Committee of the Department of Obstetrics and Gynecology, FCM/CAISM/Unicamp. All women signed a written informed consent term, also giving permission to photograph the lesions for scientific publications and teaching. All cases whose previously established diagnosis had been vulvar malignancy were excluded from the study. Social demographic characteristics were studied (age, marital status, parity, school education), general personal history (allergy, smoking, sexually transmitted disease), sexual personal history (number of partners, frequency of sexual intercourse, use of routine vaginal douche) and presence of mucocutaneous lesions (Table 1). Ulcers were macroscopically observed during clinical examination with the naked eye and/or were magnified ten times with a magnifying glass. Ulcer features described were: diameters; border characteristics; depth of the lesions; type of exudate whenever present, related to the number of ulcers and length of the clinical course; tenderness to touch; and presence of locoregional lymphadenopathy. To better locate the lesions and for didactic purposes, the vulvar area was divided into 4 quadrants with median line on the vaginal introitus (Figure 1). FGU material was collected for microbiologic study and vaginal material was collected for $\mathrm{pH}$ measurement, amine test and bacterioscopic exam. Blood samples were drawn by the Central Laboratory of Unicamp for performance of serologic tests. The Laboratory of Clinical Pathology (Unicamp) was responsible for the histopathologic diagnosis. A definitive diagnosis was established by taking clinical, serologic and histologic aspects into consideration. At each patient's visit to the health service, a routine dermatologic exam was performed, inspecting the whole tegument of the woman to detect any mucocutaneous alterations, followed by a gynecologic exam. A punch biopsy of the ulcer measuring $3 \mathrm{mM}$ in diameter was performed, removing a fragment that included normal and affected areas within the same biopsy sample. Microbiologic exam of the vagina was performed by collecting 2 samples of vaginal discharge, obtained from the lateral wall of the upper third of the vagina. The first sample was spread on a glass slide, without fixing solutions and air dried. The second sample was collected with a cotton swab and immersed in $1 \mathrm{~mL}$ of saline solution in a sterile glass. In cases of single lesions, lymph was obtained by digital expression of the lesion, and dark-field microscopic examination of material from genital ulcers was performed at the Laboratory of Microbiology of HC-UNICAMP. At the time of patient consultation, the slide was mounted, air dried and Gram-stained. Slides were analyzed using a microscope with a magnification of $\mathrm{x} 400$ for the fresh exam and $\mathrm{x} 1000$ for the Gram-stained exam immersion objective, respectively, no longer than 2 hours after material was collected. Initial consistency of all data keyed in and possible errors was performed by manual checking followed by final logical consistency. On completion of the database, data was exported to the SAS ${ }^{\circledR}$, program, version 8.2, where univariate analysis was performed.

\section{Results}

A total of $110 \mathrm{GU}$ were found in the 53 cases studied; 9 (17\%) cases had single ulcers and 44 (83\%) cases had multiple lesions. The main site for FGU (Figure 1) was the lower median region (45.8\%), followed by the upper median region (18\%). In $77.3 \%$ of the cases, ulcers were shallow and produced local pain in $92.4 \%$. The borders were irregular in $75.4 \%$, with seropurulent exudate in $49 \%$ of the cases (Table 2).

In our social setting, the results showed that $54.7 \%$ of GU cases were related to STD; $52.83 \%$ of these cases were caused by genital herpes and only $1.89 \%$ was caused by syphilis (primary chancroid). In the remaining $45.3 \%$ of the cases, genital ulcers resulted from non-sexually transmitted diseases. There was 1 case of VIN, 5 cases of Behçet's disease, 5 cases of hidradenitis suppurativa, 3 cases of ulcerative lichen 
Table 1. General, sexual, gynecologic-obstetric characteristics of 53 women with genital ulcers

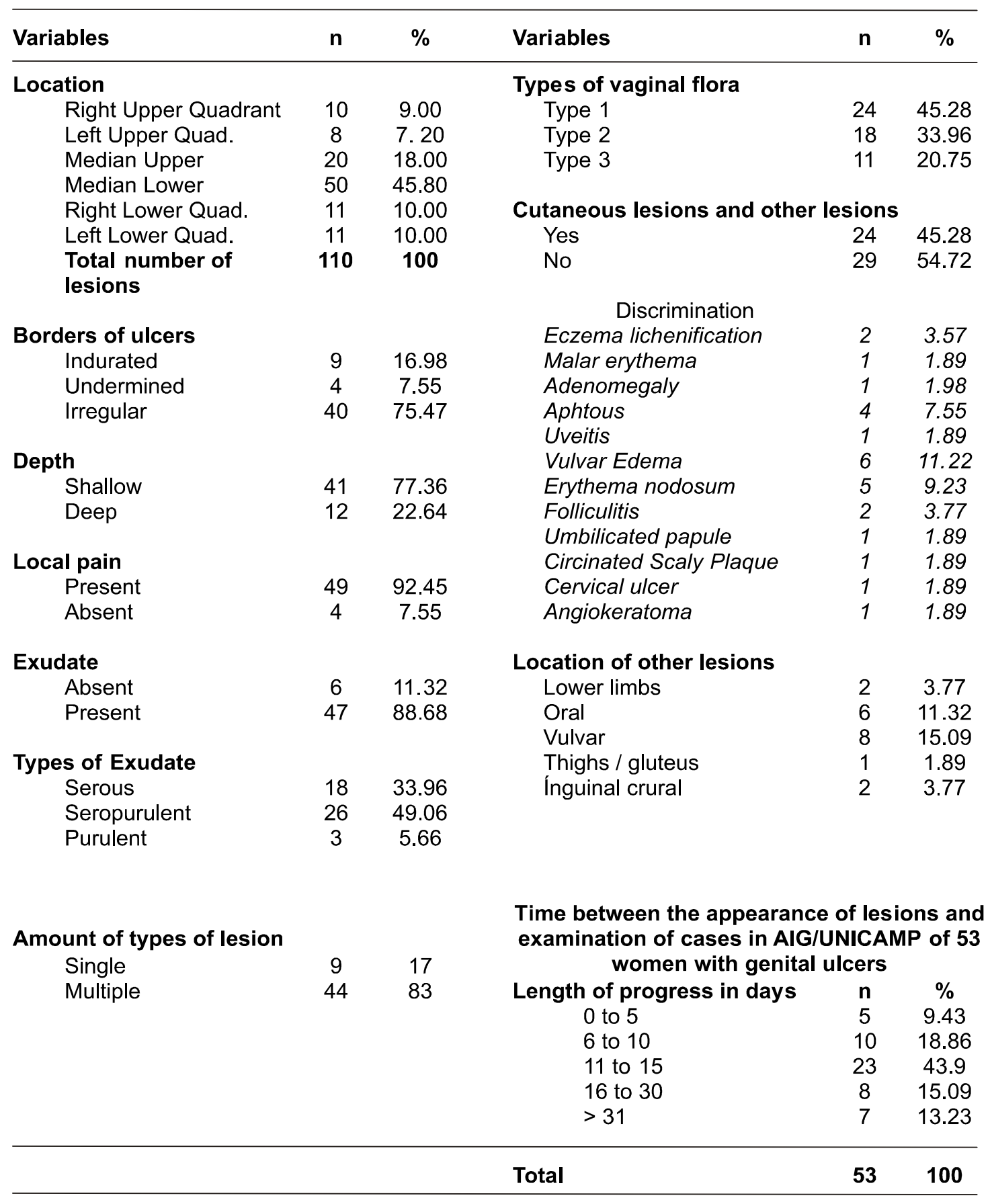


Table 2. General anatomic characteristics of female genital ulcers and other organic alterations in 53 women

\begin{tabular}{|c|c|c|c|c|c|}
\hline Variables & $\mathbf{n}$ & $\%$ & Variables & $\mathbf{n}$ & $\%$ \\
\hline Location & & & Types of vaginal flora & & \\
\hline Right Upper Quadrant & 10 & 9.00 & Type 1 & 24 & 45.28 \\
\hline Left Upper Quad. & 8 & 7. 20 & Type 2 & 18 & 33.96 \\
\hline Median Upper & 20 & 18.00 & Type 3 & 11 & 20.75 \\
\hline Median Lower & 50 & 45.80 & & & \\
\hline Right Lower Quad. & 11 & 10.00 & Cutaneous lesions and othe & sions & \\
\hline Left Lower Quad. & 11 & 10.00 & Yes & 24 & 45.28 \\
\hline \multirow[t]{2}{*}{$\begin{array}{l}\text { Total number of } \\
\text { lesions }\end{array}$} & 110 & 100 & No & 29 & 54.72 \\
\hline & & & Discrimination & & \\
\hline Borders of ulcers & & & Eczema lichenification & 2 & 3.57 \\
\hline Indurated & 9 & 16.98 & Malar erythema & 1 & 1.89 \\
\hline Undermined & 4 & 7.55 & Adenomegaly & 1 & 1.98 \\
\hline \multirow{2}{*}{ Irregular } & 40 & 75.47 & Aphtous & 4 & 7.55 \\
\hline & & & Uveitis & 1 & 1.89 \\
\hline Depth & & & Vulvar Edema & 6 & 11.22 \\
\hline Shallow & 41 & 77.36 & Erythema nodosum & 5 & 9.23 \\
\hline \multirow[t]{2}{*}{ Deep } & 12 & 22.64 & Folliculitis & 2 & 3.77 \\
\hline & & & Umbilicated papule & 1 & 1.89 \\
\hline Local pain & & & Circinated Scaly Plaque & 1 & 1.89 \\
\hline Present & 49 & 92.45 & Cervical ulcer & 1 & 1.89 \\
\hline Absent & 4 & 7.55 & Angiokeratoma & 1 & 1.89 \\
\hline Exudate & & & Location of other lesions & & \\
\hline Absent & 6 & 11.32 & Lower limbs & 2 & 3.77 \\
\hline \multirow[t]{2}{*}{ Present } & 47 & 88.68 & Oral & 6 & 11.32 \\
\hline & & & Vulvar & 8 & 15.09 \\
\hline Types of Exudate & & & Thighs / gluteus & 1 & 1.89 \\
\hline Serous & 18 & 33.96 & Ínguinal crural & 2 & 3.77 \\
\hline Seropurulent & 26 & 49.06 & & & \\
\hline Purulent & 3 & 5.66 & & & \\
\hline \multicolumn{3}{|l|}{ Amount of types of lesion } & \multicolumn{3}{|c|}{$\begin{array}{l}\text { Time between the appearance of lesions and } \\
\text { examination of cases in AIG/UNICAMP of } 53\end{array}$} \\
\hline & 9 & 17 & women with genita & Icers & \\
\hline \multirow[t]{7}{*}{ Multiple } & 44 & 83 & Length of progress in days & $\mathrm{n}$ & $\%$ \\
\hline & & & 0 to 5 & 5 & 9.43 \\
\hline & & & 6 to 10 & 10 & 18.86 \\
\hline & & & 11 to 15 & 23 & 43.9 \\
\hline & & & 16 to 30 & 8 & 15.09 \\
\hline & & & $>31$ & 7 & 13.23 \\
\hline & & & Total & 53 & 100 \\
\hline
\end{tabular}

Table 3. Frequency of clinical/laboratory etiological diagnoses of 53 female genital ulcers

\begin{tabular}{llcc}
\hline Lesion & & $\mathbf{n}$ & $\%$ \\
\hline \multirow{2}{*}{ STD } & Herpes & 28 & 52.83 \\
& Syphilis & 1 & 1.89 \\
\multirow{2}{*}{ Non-STD } & Soft Chancre & 0 & 0 \\
& & & \\
& NIV & 1 & 1.89 \\
& Behçet & 5 & 9.43 \\
& Hydradenitis & 5 & 9.43 \\
& Lichen simplex & 3 & 5.66 \\
& Pemphigus vulgaris & 1 & 1.89 \\
& Autoimmune ulcer (Pseudo & 9 & 16.98 \\
& Behçet) & & \\
\hline \multirow{2}{*}{ Total } & & $\mathbf{5 3}$ & $\mathbf{1 0 0}$ \\
\hline
\end{tabular}


Table 4. Association between clinical/laboratory diagnosis and histopathologic results of 53 cases of female genital ulcers

\begin{tabular}{|c|c|c|c|c|c|c|c|c|c|}
\hline \multirow{2}{*}{$\begin{array}{l}\text { Histologic } \\
\text { Diagnosis }\end{array}$} & \multirow[b]{2}{*}{ Herpes } & \multirow[b]{2}{*}{ Syphilis } & \multirow[b]{2}{*}{ VIN } & \multicolumn{4}{|c|}{ Clinical Laboratory Diagn. } & \multirow[b]{2}{*}{$\begin{array}{c}\text { Pseudo - } \\
\text { Behçet }\end{array}$} & \multirow[b]{2}{*}{$\mathrm{UICP}^{* *}$} \\
\hline & & & & Behçet & $\begin{array}{l}\text { Hidra } \\
\text { denitis }\end{array}$ & Lichen & $\begin{array}{l}\text { Pemphi } \\
\text { gus }\end{array}$ & & \\
\hline Herpes & 10 & & & & & & & & \\
\hline \multicolumn{10}{|l|}{ Syphilis } \\
\hline $\mathrm{VIN}^{*}$ & & & 1 & & & & & & \\
\hline Behçet & & & & 1 & & & & & \\
\hline Hidradenitis & & & & & 1 & & & & \\
\hline Lichen & & & & & & 1 & & & \\
\hline Pemphigus & & & & & & & 1 & & \\
\hline \multicolumn{10}{|c|}{ Pseudo-Behçet } \\
\hline UICP ** & 18 & 1 & & 4 & 4 & 2 & & 9 & \\
\hline Total & 28 & 1 & 1 & 5 & 5 & 3 & 1 & 9 & 0 \\
\hline
\end{tabular}

* VIN - Vulvar Intra-epithelial Neoplasm. **UICP - Unspecific Inflammatory Chronic Process. Kappa=0.0208 - I.C. 95\%(-0.0754; 0.0337).

Table 5. Cases with genital ulcer using medication at the time of first consultation

\begin{tabular}{lcccccr}
\hline & Adequate Treatment & \multicolumn{2}{c}{ Inadequate Treatment } & \multicolumn{2}{r}{ No Treatment } \\
\hline STD & $\mathbf{n}$ & $\%$ & $\mathbf{n}$ & $\%$ & $\mathbf{n}$ & $\%$ \\
Herpes & 1 & 3.57 & 8 & 28.58 & 19 & 67.85 \\
Syphilis & 0 & 0 & 0 & 0 & 1 & 100 \\
Non-STD & & & & & & \\
& 0 & 0 & 1 & 100 & 0 & 0 \\
Behçet & 0 & 0 & 5 & 100 & 0 & 0 \\
Hidradenitis & 0 & 0 & 3 & 60 & 2 & 40 \\
Lichen & 0 & 0 & 3 & 100 & 0 & 0 \\
Pemphigus & 0 & 0 & 1 & 100 & 0 & 0 \\
Pseudo-Behçet & 0 & 0 & 9 & 100 & 0 & 0 \\
\hline Total & $\mathbf{1}$ & $\mathbf{3 . 5 7}$ & $\mathbf{3 0}$ & $\mathbf{5 6 . 6}$ & $\mathbf{2 2}$ & $\mathbf{4 1 . 5 1}$ \\
\hline
\end{tabular}


Figure 1. Diagram with different regions where female genital ulcers are located.

\section{Topography of genital ulcer sites}

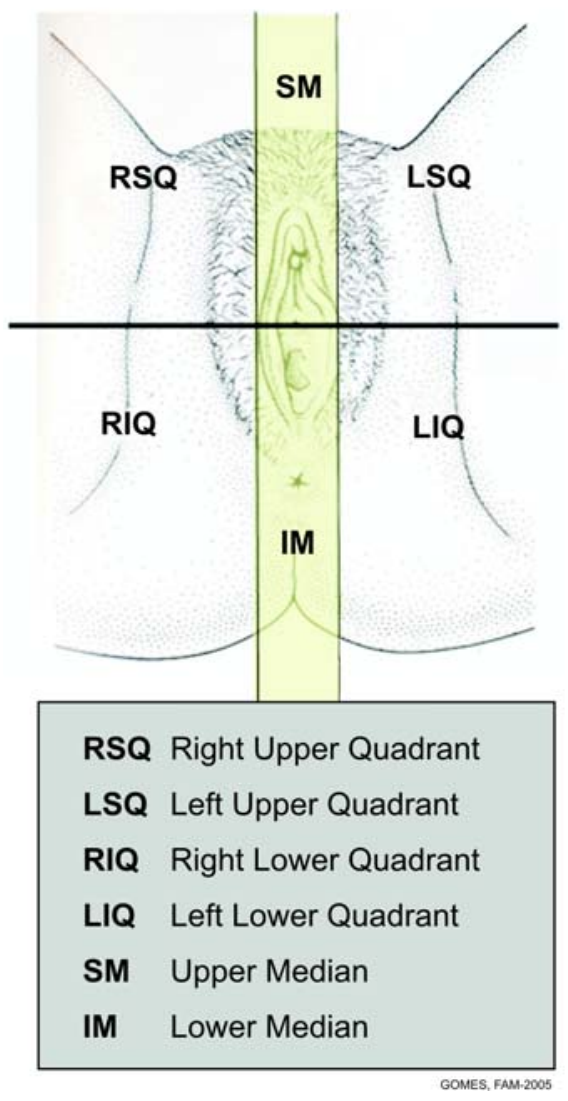

sclerosis simplex, 1 case of pemphigus vulgaris and 9 cases of pseudo-Behçet's disease, totaling 26.4\% of auto-immune cases (Tables 3 and 4). The clinical course lasted an average of 18 days. It was interesting to note that at the time of the first visit, $56.6 \%$ of the women had been using medication that was inadequate and inconsistent with the final diagnosis (Table 5). Histologic diagnosis (Table 4) was conclusive in only 5 out of 53 cases, and unspecific chronic inflammatory process was reported in $71.7 \%$ of the cases (Kappa=-0.0208).

The average age of the patients was 32 years $( \pm 14.5 \%)$, and $69.8 \%$ were between 20 and 40 years. Approximately $60 \%$ were married or unmarried but living with a partner (stable sex partner), 56.6\% had a junior high school or higher education and $81.1 \%$ were non-smokers. Forty-one per cent (41\%) were nullipara, and $77.3 \%$ had a history of at least 1 abortion. In our observations, $7.5 \%$ of the women had no sexual intercourse and only $30.1 \%$ had more than 4 lifetime partners. Most of these women (74.2\%) had between 1 and 3 sexual intercourses per week, and $90.5 \%$ did not use hygienic douches. Condom use was not regular in $60.4 \%$ and only $22.6 \%$ practiced masturbation. Of the contraceptive methods, the pill was the most frequently used (47.1\%) and only 9.3\% of the women used a diaphragm. A history of allergies was present in only one-fourth of the cases (26.4\%), and most of these were respiratory allergies. The history of previous STD was rare and occurred in only $18.8 \%$ (Table 1 ).

\section{Discussion}

We observed a total of 53 cases. In this group of women, a non-sexually transmitted cause accounted for $45.28 \%$ of the genital ulcer cases, while sexually transmitted diseases accounted for $54.72 \%$ of the cases, corroborating data of the current literature [6]. However, among the STD, the main cause of genital ulcers was herpetic and not syphilitic, as one would expect in developing countries such as Brazil. A possible explanation for this finding is the geographical location where the study was conducted in our country, i.e. the southeastern region. The population living in this region has a higher sociocultural status (56.61\% had at least completed junior high school education). The very low rates of bacterial STD certainly expressed a better level of patient information. Another aspect worth mentioning is that among the women studied, none were commercial sex workers or had been infected with the human immunodeficiency virus.

Fifty-six per cent (56\%) of the women were taking inadequate medication at the time of their first visit to the outpatient facility due to misdiagnosis. Therefore, in this type of population studied, treatment guided by the flow chart for syndromic management of STD was ineffective. In cases of genital herpes, only $3.57 \%$ of those referred to our service had been using adequate medication prior to their first consultation. Treatment was inadequate in $28.58 \%$ of the patients and $67.85 \%$ of the patients arrived without any previous counseling or treatment. Nevertheless, it is worth highlighting that syndromic management of FGU can be appropriate and effective in other geographic locations, even in certain Brazilian regions, where the prevalence of bacterial STD may be higher. We believe that application of a flow chart for syndromic management should be encouraged, since it may be the only tool available for the healthcare provider to combat STD/AIDS. Abstinence from sexual intercourse in the presence of genital ulcers or genital inflammatory processes is a major recommendation for patients affected, along with condom use and performance of specific serologic tests. We must also understand that the flow chart for syndromic management should not be indistinctly applied to all cases of genital ulcers, particularly in Brazil, unless there is no other recourse. In our country, the cultural and social demographic diversity is considerable.

All patients with genital ulcers had their diagnoses established and were treated according to specific protocols for each disease found. Clinical course was favorable in (99\%) of the cases. Only 1 patient could not be assessed due to spontaneous loss of follow-up in our service (case excluded). The clinical course of her disease was radically different from that found in other similar cases, before the patients first visited our outpatient facility. Many other patients probably had achieved success in the syndromic management of their 
diseases and did not require a referral to our outpatient facility. The majority of ulcers were located in the midline near the clitoris or vaginal introitus in a region called median topography. A probable explanation is that there is greater friction and contact in that region, facilitating the appearance of local disease. The frequency of sexual intercourse, number of sexual partners, practice of masturbation and vaginal douching did not correlate with the presence of FGU.

In general, it has been observed that clinical medicine supported by an appropriate history and a coherent physical examination, remains the cornerstone of diagnosis and treatment of FGU, according to the ancient and classical paradigm. We should not forget that in cases of FGU, histology examination was not considered the gold standard for diagnosis as in many other disorders, because it revealed only 1 chronic ulcerative inflammatory and unspecific process in 38 cases (71.69\%), expressing a low accuracy rate.

\section{References}

1. Young A.W. Jr., Tovell H.M., Sadri K. Erosions and ulcers of the vulva: diagnosis, incidence and management. Obstet Gynecol 1977;50:35-9.

2. Edwards L. Diseases and disorders of the anogenitalia of females. In: Fitzpatrick's T. Dermatology in General Medicine 5 edition. United States of America: McGraw Hill; 1999:1376-95.

3. Sampaio S.A.P., Rivitti E. Pele normal:anatomia e fisiologia. In:

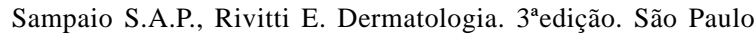
Artes Médicas; 2001:3-35.

4. Brasil. Ministério da Saúde. Manual Controle Sexually transmitted diseases - 1999.

5. Engelkens H.J.H., Stoltz E. Genital ulcer disease. Int J Dermatol 1993:169-81.
6. Bruisten S.M. Genital ulcer in women. Curr Womens Health Rep 2003;3:288-98.

7. Pinotti J.A., Miranda S.D., Maestri C.A., et al. Genital ulcers na Mulher. Rev Gin Obstet 1998;1:46-53.

8. Tenorio T. Infecções Sexualmente Transmissíveis Caracterizadas por Genital ulcers. Femina 2001;29:635-7.

9. Kassler W.J., Cates W. Jr. The epidemiology and prevention of sexually transmitted diseases. Urol Clin North Am 1992;19:1-5.

10. Giraldo P.C., Ribeiro-Filho A.D., Yesões J.A., et al. Vulvovaginites - aspectos habitualmente não considerados. J Bras Ginec 1997; 107:89-93.

11. Wasserheit J.M. Effects of changes in human ecology and behavior on patterns of sexually transmitted disease, including human immunodeficiency virus infections. Proci Natl Acad Sci USA 1994:91:2430.

12. Laga M. Epidemiology and control of sexually transmitted diseases in developing countries. Sex Transm Dis 1994;21(suppl 2):45-50.

13. Fleming D.T., Wasserheit J.N. From epidemiological synergy to public health policy and practice: the contribution of other sexually transmitted disease to sexual transmission of HIV infection. Sex Trasm Infect 1999;75:3-17.

14. Kamali A., Nunn A.J., Mulder D.W., et al. Seroprevalence and incidence of genital ulcer infections in a rural Ugandan population. Sex Transm Infect 1999;75:98-102.

15. Chen C.Y., Ballard R.C., Beck-Sague C.M., et al. Human immunodeficiency virus infection and genital ulcer disease in South Africa: the herpetic connection. Sex Transm Dis 2000;21-31.

16. Cigielski J.P. Epidemiology of Aids in Africa (part 2). Int Health News 1988;9:8-9.

17. Lottery H.E., Galask R.P., Stone M.S., Sontheimer R.D. Ulcerative vulvitis in atypical Reiter's syndrome. J Am Acad Dermatol 2003;48:613-6.

18. Rogers III R.S. Pseudo-Behçet's disease. Dermatol Clin 2003;21:49-61.

19. Rogers III R.S. Eisen D. Erosive oral lichen planus with genital lesions: The vulvovaginal-gengival syndrome and the penisgingival syndrome. Dermatol Clin 2003;21:91-8. 